\title{
Apresentação - Linguística: Sintaxe e suas interfaces
}

Ana Maria Tramunt Ibaños ${ }^{1}$, Gabriel de Ávila Othero ${ }^{2}$, Ana Paula Correa da Silva Biasibetti ${ }^{3}$

Doutora em Linguística e professora do Programa de Pós-Graduação em Letras da Pontifícia Universidade Católica do Rio Grande do Sul (PUCRS)

atibanos@pucrs.br

2 Doutor em Linguística e professor do Programa de Pós-Graduação em Letras da Universidade Federal do Rio Grande do Sul (UFRGS)

gab.othero@gmail.com

Doutoranda em Linguística na Pontifícia Universidade Catolica do Rio Grande do Sul (PUCRS). Bolsista CNPq. sta edição traz textos relativos ao estudo sintático em suas diversas interfaces: com a Fonologia, com a Morfologia, com a Prosódia, com a Semântica, com a Pragmática e com Estudos de Gênero Textual. Essa multiplicidade de interfaces, que apresenta como base um fenômeno sintático, faz com que tenhamos artigos com focos diversos, dependendo da escolha interdisciplinar feita pelos autores.

Ora, acreditamos que o estudo da sintaxe de uma língua natural (como o português, por exemplo) é central para seu entendimento e para a compreensão do funcionamento da gramática dessa língua. Contudo, às vezes o estudo de determinado fenômeno de natureza essencialmente sintática pode extrapolar os limites da sintaxe. Por exemplo: a ordem de palavras na sentença (um fenômeno a priori essencialmente sintático) pode sofrer a influência de fatores que vão além da sintaxe, como fatores de ordem prosódica ou comunicativa. Imaginemos a resposta a uma pergunta como (1):

(1) Que livro o João leu?

Uma resposta possível à pergunta (1) poderia ser (2):

(2) João leu Dom Casmurro.

A resposta em (2) parece adequada, pois (entre outras coisas) respeita a ordem de constituintes básica da sentença em português: SVO (sujeito-verbo-objeto). Repare que, em termos prosódicos, costumamos produzir (2) com um acento 
final mais marcado, algo como 'O João leu DOM CASMURRO', em que as letras maiúsculas representam um acento mais proeminente; essa observação será importante para a discussão que desenvolveremos aqui.

Vejamos outra pergunta, agora:

(3) Quem leu Dom Casmurro?

Imagine que tenhamos duas maneiras possíveis de formular uma resposta à pergunta acima, (4) e (5). Qual das duas parece mais natural?

Quem leu Dom Casmurro?

(4) Foi o João.

Quem leu Dom Casmurro?

(5) O João leu Dom Casmurro.

Repare como aqui, nas respostas possíveis à pergunta (3), temos a tendência a usar (4) como resposta. Ou, se preferimos (5), marcamos o sintagma [o João] com um acento tonal diferenciado (algo como 'O JOÃO leu Dom Casmurro'). Isso acontece porque uma frase bem formada da língua deve responder a uma série de "demandas”: sintáticas, prosódicas, comunicativas, etc.

Por exemplo, em termos sintáticos, a língua portuguesa favorece sentenças com a organização SVO (é a chamada "ordem direta" da língua, reconhecida inclusive pela tradição gramatical); em termos prosódicos, as frases do português tendem a respeitar o princípio de marcar o último constituinte com um acento diferenciado; já em termos informacionais, há dois princípios que costumamos respeitar: o de deixar a informação nova na posição final da frase e o de marcar essa informação nova com um acento diferenciado.

Retornando ao par (1) e (2), vemos que (2) é uma ótima resposta a (1), pois (2) consegue corresponder a todas as exigências que elencamos no parágrafo anterior: ela é uma sentença (i) que respeita a ordem SVO (O João - leu - Dom Casmurro), (ii) em que o último constituinte recebe o acento mais proeminente (DOM CASMURRO) e (iii) que deixa a informação nova (Dom Casmurro), justamente aquela que o interlocutor questiona em sua pergunta, em posição final e como já mencionamos - com o acento proeminente. 
Entretanto, o mesmo não acontece com as respostas sugeridas para a pergunta (3). Aliás, não há como termos uma resposta possível para (3) que consiga satisfazer simultaneamente todas as exigências que elencamos acima. Como a informação nova agora será o sujeito da frase ( $O$ João), então ela não pode aparecer na posição final da frase, a menos que a ordem SVO seja violada. Nesse caso, teríamos uma resposta como 'Leu Dom Casmurro o João', que não é uma boa opção (pelo menos não em português brasileiro (PB); em português europeu, essa é de fato uma resposta muito natural à pergunta (3)). Por outro lado, se satisfizermos o princípio sintático de manter o ordenamento da frase com a ordem SVO, então a informação nova (O João) estará no começo da sentença, contrariando o princípio de organização informacional, que postula que a informação nova deve vir no final da frase, depois da informação velha. Finalmente, para o que o acento mais proeminente da frase recaia sobre a informação nova, nesse caso teremos de violar o princípio prosódico que pede para que o acento proeminente fique com o último constituinte da frase. Eis aqui uma bela charada para a sintaxe, então.

De que maneira a língua resolve essa questão? Vimos que há duas respostas naturais para a pergunta 'Quem leu Dom Casmurro?':

(4) Foi o João.

(5) 0 João leu Dom Casmurro.

Em (4), a ordem SVO é violada, em prol de satisfazermos os princípios prosódicos e informacionais. Ou seja, ao não mantermos a ordem SVO, conseguimos (i) marcar o último constituinte com um acento diferenciado; (ii) deixar a informação nova na posição final da frase e (iii) marcar essa informação nova com um acento diferenciado. É uma solução possível, em que o princípio sintático estrito deixa de ter papel crucial.

Em (5), por outro lado, o princípio sintático é respeitado: a frase apresenta-se na ordem SVO. E um dos princípios informacionais também é seguido: o constituinte que veicula informação nova carrega o acento principal da frase: 'Quem leu Dom Casmurro? O JOÃO leu Dom Casmurro'. Em contrapartida, para que o princípio sintático de ordenamento SVO pudesse ser respeitado, o princípio prosódico e o princípio informacional de veicular a informação nova no final da frase foram desrespeitados. Em PB, essa também é uma solução possível. Vemos aqui, então, uma interface entre o módulo sintático e outros módulos gramaticais.

Vejamos um outro fenômeno sintático - típico do PB - que também envolve questões de interface, dessa vez com a semântica: o objeto nulo ${ }^{1}$.

${ }^{1}$ Sobre objeto nulo em PB, a literatura é vasta. Talvez uma primeira aproximação ao assunto possa ser o artigo de Mileski (2014), que traz um panorama atual do assunto. 
Em PB, há algum tempo já temos evitado de usar o clítico acusativo de terceira pessoa, o, a, os, as. Repare como estas frases soam pouco naturais em PB falado:

(6) O João conheceu a Maria e beijou-a no minuto seguinte.

(7) O João ganhou um livro, mas perdeu-o no minuto seguinte.

Ao invés de usarmos o clítico, o PB desenvolveu duas estratégias inovadoras para a retomada de objetos diretos de terceira pessoa: o uso do pronome tônico de terceira pessoa (ele, ela, eles, elas) e o uso de um elemento nulo (que representaremos pelo símbolo $\emptyset$, de vazio, nos exemplos abaixo). Repare como as frases (8) e (9) soam mais naturais em $\mathrm{PB}$, quando comparadas com (6) e (7):

(8) 0 João conheceu a Maria e beijou ela no minuto seguinte.

(9) O João ganhou um livro, mas perdeu Ø no minuto seguinte.

Entretanto, essas duas formas (pronome tônico e objeto nulo) não são usadas indiscriminadamente. Parece haver aqui uma preferência por usarmos um pronome quando o antecedente tiver o traço semântico de animacidade. Ou seja, quando o antecedente for [+animado], usa-se o pronome tônico. De maneira inversa, temos a tendência de usar o objeto nulo quando o referente tiver o traço semântico [-animado]. Repare como as frases em (10) e (11) soam menos naturais do que (8) e (9):

(10) ? O João conheceu a Maria e beijou Ø no minuto seguinte.

(11) ? O João ganhou um livro, mas perdeu ele no minuto seguinte.

Isso acontece porque, aqui, em (10) e (11), fizemos a retomada de um antecedente animado ([a Maria]) com um objeto nulo (Ø); e a retomada de um antecedente não animado ([um livro]) com um pronome (ele). Ambas as frases continuam sendo gramaticais; entretanto, nossa intuição diz que há aí uma escala de aceitabilidade, em que (8) e (9) são mais aceitáveis do que suas contrapartes em (10) e (11).

Esses exemplos serviram para ilustrar como fenômenos de natureza intrinsicamente sintática (como a ordem de palavras e o uso de complemento verbal) podem (e devem?) ser explicados levando-se em conta as interfaces que o módulo 
sintático faz com outros componentes gramaticais (como com os componentes semântico, prosódico, informacional, etc.). Apresentamos aqui, evidentemente, apenas um brevíssimo esboço de análise em cada caso ${ }^{2}$, com o mero intuito de ilustrar o nosso ponto central: há muita coisa a ser investigada nas interfaces da Sintaxe. Agora, convidamos o leitor a navegar pelas páginas desta edição da Revista Letrônica para conhecer trabalhos originais e inéditos que lidam com fenômenos sintáticos em suas diversas interfaces. São 15 artigos, de 25 autores, representando diversas universidades e centros de pesquisa.

Começamos a edição com o artigo Reflexividade, foco e a vogal -i- do georgiano, de João Paulo Lazzarini-Cyrino, cujo tópico é analisar as estratégias de reflexivização do georgiano à luz da proposta de Hornstein $(1999,2001)$ e argumentar que o morfema -i- não é um operador de valência verbal, mas uma realização de uma cópia incorporada do argumento interno do verbo. No segundo artigo, Verbos aspectuais: alternância argumental, Luana Lopes Amaral propõe uma análise para a alternância sintática que ocorre com os verbos aspectuais, descartando que a alternância em jogo seja da relação verbal causativa-incoativa, mas uma alternância argumental do predicador encaixado, que é argumento do aspectualizador. O terceiro texto, Interface Sintaxe-Semântica: em defesa de uma abordagem construcionista para a ordem VS do português brasileiro, de Diogo Pinheiro e Lílian Ferrari, busca mostrar, dentro do quadro teórico da Gramática de Construções (GOLDBERG, 1995, 2006; CROFT, 2001), que o esquema verbo-sujeito do português brasileiro se constitui como uma unidade simbólica, ou seja, uma construção gramatical. O quarto texto, A ordem VS em sentenças imperativas do português brasileiro, de Rerisson Cavalcante e Leonor Simioni, também aborda o tópico de ordem VS, no caso de construções imperativas, mas na interface sintaxe-pragmática. Através da descrição e análise de vários contextos pragmáticos de uso de sentenças imperativas, os autores contrapõem a literatura sobre a posição dos constituintes no português, que considera que a ordem VS em imperativas é o resultado do movimento V-para-C.

Deixando a língua portuguesa como foco de estudo, o quinto texto, de Rachel Antonio Soares, As causativas na língua japonesa, aborda os três tipos de construções causativas em japonês, a saber, lexical, sintática e zero, com o objetivo de contribuir para o estudo dessas questões gramaticais nessa língua. 0 texto Construções de posse predicativa na Língua Apurinã (Aruák), de Marília Pereira de Freitas e Sidi Facundes, é o sexto texto desta edição da Letrônica e apresenta resultados das pesquisas de campo realizadas em 2014 e 2015, abordando as principais questões relativas à codificação linguística da posse em construções verbais da língua Apurinã.

No sétimo artigo, intitulado Sintaxe e prosódia: antissimetria, hierarquia e isomorfismo, Pablo Faria assume que a antissimetria da sintaxe é definidora da hierarquia prosódica. Além disso, o autor opõe-se fundamentalmente às

2 Para saber mais sobre a ordem de palavras em PB, envolvendo as questões que mencionamos aqui, cf. Othero \& Figueiredo Silva (2012), por exemplo. Sobre o objeto nulo, há o texto clássico de Cyrino (1997). 
propostas de Selkirk (1980) e Nespor \& Vogel (1986) ao defender que há isomorfismo entre os constituintes sintáticos e prosódicos e que tal propriedade é importante para a avaliação das representações sintáticas. Em Verbos-suporte dar/levar: um caso de gramaticalização?, o oitavo artigo desta edição, Aucione Smarsaro e Violeta Virginia Rodrigues investigam o uso dos verbos-suporte dar/levar seguidos de nomes predicativos em orações como João deu um fora em Maria = Maria levou um fora de João, a exemplo, a fim de verificar sob os pressupostos teóricos do Léxico-Gramática (GROSS, 1975) e dos Parâmetros de Gramaticalização (HEINE; CLAUDI; HUNNEMEYER, 1991) se tais estruturas são palavras gramaticais. No nono artigo, uma análise funcionalista é desenvolvida por Tatiana Schwochow Pimpão em Pressuposição e a variação no presente do modo subjuntivo com o objetivo de analisar se a variação entre o presente do modo subjuntivo e o presente do modo indicativo em orações concessivas introduzidas por embora, apesar de que e se bem que, em orações causais introduzidas por não e em orações parentéticas é utilizada como estratégia pragmática de correção da pressuposição. Em Caracterização semântico-pragmática de tópicos pendentes no português brasileiro, décimo artigo, Tatiane Macedo Costa e Aroldo Leal de Andrade investigaram as construções de Tópico Pendente e de Deslocação à Esquerda de Tópico Pendente em dois corpora a partir dos pressupostos da Teoria da Representação do Discurso Segmentado (ASHER, LASCARIDES, 2003). A análise dos dados sugere que as referidas construções consistem em unidades discursivas distintas que se relacionam ao contexto por subordinação e ao comentário por enquadramento ou atribuição.

Violeta Virginia Rodrigues e Adriana Cristina Lopes Gonçalves são as autoras do décimo primeiro texto, intitulado Comprou, levou? Justaposição: procedimento sintático comum em propagandas. Fundamentada na teoria funcionalista, a análise de dados provenientes de campanhas publicitárias objetiva estabelecer as diferenças entre os casos de coordenação e os de justaposição, concentrando-se nas propriedades semânticas e prosódicas de cada processo. No décimo segundo texto, intitulado Reflexos semânticos na sintaxe de terceira pessoa, Fernanda de Oliveira Cerqueira realiza um estudo sobre a hierarquia de traços que constitui o pronome ele acusativo a fim de identificar o papel que os traços semânticos [Definido], [Específico] e [Animado] podem exercer na sintaxe. Orações adverbiais introduzidas pelos transpositores sem/sem que: relação entre a ordem da oração satélite e os propósitos comunicativos de Camilo Rosa Silva e Marta Anaisa Bezerra Ramos é o décimo terceiro texto desta edição, o qual explora a relação entre a ordem e as funções textualdiscursivas das orações satélites introduzidas pelos transpositores sem/sem que. Os autores desenvolvem a tese de que tais estruturas oracionais decorrem da interferência semântica resultante da relação entre a oração nuclear e a oração satélite (iconicidade semântica) assim como da função discursiva da oração satélite (iconicidade discursiva). Nize da Rocha Santos Paraguassu Martins e Rivanildo da Silva Borges são os autores do décimo quarto artigo, A semântica dos nomes 
nus no português brasileiro falado em Teresina - PI, o qual analisa dados de fala com o objetivo de identificar as posições em que os nomes nus ocorrem, as interpretações por eles licenciadas e a possibilidade de denotarem espécie. Por fim, $\boldsymbol{A}$ linguagem da bula: um estudo de estruturas linguísticas do gênero, de Carmelita Minelio da Silva Amorim, Lúcia Helena Peyroton da Rocha e Maria José Costa, trata das construções passivas presentes nos textos de bulas de medicamentos em face às exigências mais recentes da Agência Nacional de Vigilância Sanitária (ANVISA) no que concerne ao uso de uma linguagem mais clara e objetiva. Para tanto, o estudo propõe-se a investigar as diferentes estruturas linguísticas presentes nos textos das bulas que compõem o corpus analisado e as estratégias de apagamento do agente.

Boa leitura!

\section{Referências}

ASHER, N.; LASCARIDES, A. Logics of Conversation. Cambridge: Cambridge University Press, 2003.

CYRINO, Sônia. O objeto nulo no português do Brasil - um estudo sintático-diacrônico. Londrina: Editora UEL, 1997.

CROFT, William. Radical Construction Grammar: Syntactic Theory in Typological Perspective. Oxford: Oxford University Press, 2001. http:// dx.doi.org/10/1093/acprof:oso/9780198299554.001.0001

GOLDBERG, Adele. Constructions: a construction grammar approach to argument structure. Chicago: University Press, 1995.

. Constructions at work: the nature of generalization in language. Cambridge: University Press, 2006.

GROSS, Maurice. Méthodes en syntaxe. Paris: Hermann, 1975.

HEINE, Bernd; CLAUDI, U.; HUNNEMEYER, F. Grammaticalization: a conceptual framework. Chicago: University of Chicago Press, 1991.

HORNSTEIN, Norbert. Movement and Control. Linguistic Inquiry, Cambridge, Mass., v. 1, n. 30, p. 69-96, 1999. http://dx.doi.org/10.1162/ 002438999553968

. Move! A Minimalist Theory of Construal. Oxford, UK/Cambridge, Mass.: Blackwell Publishers, 2001.

MILESKI, I. Uma discussão sobre condicionamentos semânticos do uso do objeto nulo no português brasileiro. Via Litterae, v. 6, n. 2 , 2014. NESPOR, Marina; VOGEL, Irene. Prosodic Phonology. Foris: Dordrecht, 1986.

OTHERO, G. A.; FIGUEIREDO SILVA, M. C. Focalização em português: interface entre condições sintáticas, prosódicas e de estrutura informacional. In: CRUZ, R. T. (Org.). As interfaces da gramática, vol. I. Curitiba: CRV, 2012.

SELKIRK, Elisabeth. On Prosodic Structure and Its Relation to Syntactic Structure. Indiana University Linguistics Club, ms., 1980. 